\title{
Fluorine-Stabilized Acid Amplifiers for Use in EUV Lithography
}

\author{
Kenji Hosoi, ${ }^{\text {a }}$ Brian Cardineau, ${ }^{\mathrm{b}}$ Seth Kruger, ${ }^{\mathrm{b}}$ Koichi Miyauchi ${ }^{\mathrm{a}}$ and Robert Brainard ${ }^{\mathrm{b}}$ \\ a. Central Glass, Co. Ltd., Chiyoda-Ku, Tokyo, 101-0054 Japan \\ b. College of Nanoscale Science and Engineering, University at Albany, NY 12203
}

\begin{abstract}
This paper presents two new concepts that together provide a 100,000X improvement in stability for AAs that produce highly-fluorinated, strong sulfonic acids. These two new design concepts are based on (1) an olefin-trigger structure and (2) a trifluoromethyl group alpha to the sulfonic ester. These approaches led to the synthesis of the first stable acid amplifier that generates triflic acid and for the synthesis of AAs that are stable enough to be used as monomers in free-radical polymerization reactions yet produce very strong, fluorinated acids. Lastly, we present preliminary results where one new AA is able to improve the LER of a control resist from $4.6 \pm 0.5 \mathrm{~nm}$ to $2.1 \pm 0.1 \mathrm{~nm}$.
\end{abstract}

Keywords: Acid amplifier, EUV, photoresists

\section{Introduction}

Extreme ultraviolet (EUV) lithography continues to be a strong candidate for a commercially viable solution to next generation lithography. However, further development of chemically amplified photoresists for use with EUV is critical to meet the future photolithographic requirements of the microelectronics industry. EUV resists must simultaneously meet three requirements: high resolution, low line edge roughness (LER), ${ }^{1}$ and high sensitivity. ${ }^{2}$ We have proposed that the best way to simultaneously improve these three properties in EUV resists is to increase the number of strong acids generated per photon absorbed during exposure ${ }^{3}$ and we assert that acid amplifiers may be one of the best ways to achieve decompose in the presence of acid to generate more acid via acid-catalyzed mechanisms. ${ }^{4}$ When the product acid is strong enough to catalyze the decomposition of the AA, the decomposition occurs autocatalytically (Figure 1). ${ }^{5}$

Typically, acid amplifiers consist of three parts (Figure 1), a body, an acid-sensitive trigger ( $\mathrm{T}$, either hydroxyl, methoxy, acetate or ketal), and a sulfonic acid precursor

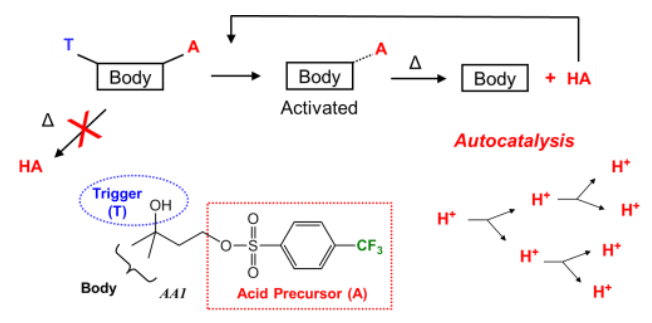

Figure 1. Generic representation of acid amplifiers (AAs). These compounds consist of three parts: a trigger $(\mathrm{T})$, an acid precursor (A) and a body.

(A). The desired acid generation pathway is via acidcatalyzed decomposition. During autocatalysis, the trigger undergoes acidolysis yielding an allylic sulfonic ester (Figure 2). This olefin intermediate allows the sulfonic ester to thermally decompose via an $\mathrm{E}_{1}$ or $\mathrm{E}_{2}$ elimination reaction more rapidly than the starting AA, yielding a second double bond alkene fragment and a sulfonic acid. The undesirable decomposition pathway is uncatalyzed thermal decomposition which results in the formation of an olefin byproduct and an acid. 


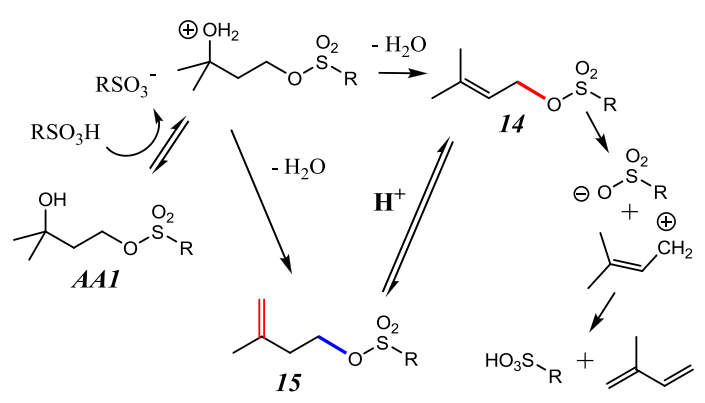

Figure 2. Proposed acid-catalyzed decomposition pathway for $\boldsymbol{A A 1}$ in which a tertiary alcohol trigger is removed to generate intermediate $\mathbf{1 4}$ containing a sulfonic ester with an allylic $\mathrm{C}-\mathrm{O}$ bond $\left(\mathrm{R}=-\mathrm{C}_{6} \mathrm{H}_{4} \mathrm{CF}_{3}\right)$.

Several acid amplifiers (20-30) were reported in the literature $^{6-13}$ prior to the beginning or our research in 2005. For the most part, these AAs generate weak sulfonic acids such as toluene sulfonic acid. Only two of these acid amplifiers produce fluorinated sulfonic acids. ${ }^{13}$ Since our interest has been to create AAs that are useful to chemically amplified photoresists, our focus has always been to create AAs that generate strong, fluorinated acids, since these acids are better catalysts and ultimately provide better lithographic performance than do weaker acids. $^{14}$ Unfortunately, however, acid amplifiers that produce the strongest acids are the least stable (in the absence of catalytic acid) and typically are unable to withstand the temperatures required for synthesis or lithography. ${ }^{15}$

Here, we present two new concepts that together provide a 100,000X improvement in stability for AAs that produce highly-fluorinated, strong sulfonic acids. These two new design concepts are based on (1) an olefin-trigger structure and (2) a trifluoromethyl group alpha to the sulfonic ester.

\section{Results and Discussion}

\subsection{Olefin-Trigger Acid Amplifiers}

All of the acid amplifiers previously reported by us ${ }^{14-18}$ and others ${ }^{4-13}$ have triggers that are leaving groups. In general, the acid activates the trigger; the trigger then leaves creating a double bond (14 in Figure 2). Since the double bond in $\mathbf{1 4}$ is allylic to the acid, the compound decomposes thermally thereby producing an acid.
We have considered that the mechanism for the development of AAs could include the generation of an olefin intermediate for which the C-O sulfonic ester bond was not allylic (15) and, therefore, would not produce acid. Yet, we also considered the additional possibility that the non-allylic 15 could be isomerized by catalytic acid to the allylic 14 as a potential pathway for producing acid. This mechanistic analysis led to the idea of using non-allylic double bonds as triggers. For example, the olefin can be positioned three carbons away from the sulfonic ester (acid precursor). In this state, there is no allylic stabilization to the acid precursor and the compound is thermally stable. The trigger is effectively in the "off" position. Isomerization of the initial olefin can occur to produce the more highly-substituted olefin which is also allylic to the sulfonic ester. In the presence of a catalytic acid, the double bond can isomerize toward the acid precursor and then thermally decompose releasing the acid.

The lithographic performance of two olefin-trigger AAs was evaluated as a function of PEB temperature (Figure 3). ${ }^{19} \boldsymbol{A} \boldsymbol{A} \boldsymbol{2}$ increases the sensitivity of the control by 0.1 to $2 \mathrm{X}$ and $\boldsymbol{A} \boldsymbol{A 3}$ increases the sensitivity of the control by 2 to $10 \mathrm{X}$, depending upon post exposure bake (PEB) temperature.

\subsection{Fluorine-Stabilized Acid Amplifiers}

One of the biggest challenges in designing and preparing acid amplifiers for use in chemically amplified

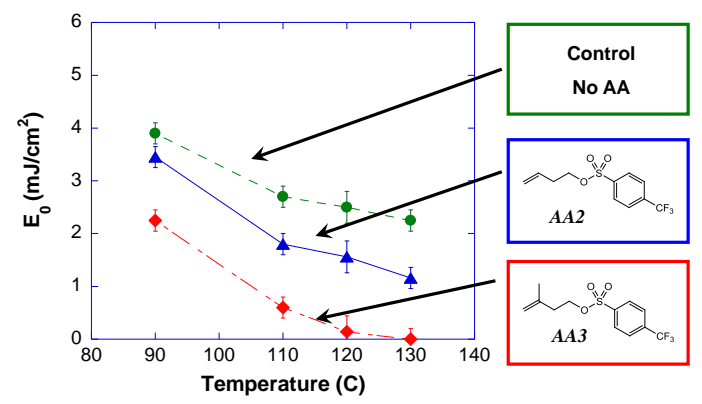

Figure 3. Clearing doses (Eo) of a control resist ${ }^{19}$ and resists prepared with $70 \mathrm{mM}$ of $\boldsymbol{A} \boldsymbol{A} \boldsymbol{2}$ and $\boldsymbol{A} \boldsymbol{A} \mathbf{3}$.

resists is that the AAs that generate fluorinated acids tend to be unstable. Product analysis experiments ${ }^{14}$ showed 
that the pathways for the unwanted, noncatalytic decomposition reactions involved either $S_{N} 2$ or $S_{N} 1$ reactions between phenolic nucleophiles in polymer films or in solution and the primary sulfonic ester bonds (Figure 4). We, therefore, devised a strategy for blocking both decomposition pathways by preparing acid amplifiers with a trifluoromethyl $\left(-\mathrm{CF}_{3}\right)$ group alpha to the sulfonic ester. We proposed that the $\mathrm{CF}_{3}$ would reduce the rate of $\mathrm{S}_{\mathrm{N}} 2$ pathway by increasing steric hindrance; and would reduce the rate of the $S_{N} 1$ pathway by preventing the buildup of positive charge.

Combining both the olefin trigger and the fluorinestabilized capacity into one trigger-body design, we produced acid amplifiers $\boldsymbol{A A 4}$ and $\boldsymbol{A A 5}$ (Figure 5), which are designed to produce pentafluorobenzene-sulfonic acid $\left(\mathrm{C}_{6} \mathrm{~F}_{5} \mathrm{SO}_{3} \mathrm{H}, \mathrm{PFBS}\right)$ and triflic acid $\left(\mathrm{CF}_{3} \mathrm{SO}_{3} \mathrm{H}, \mathrm{TfOH}\right)$, respectively. Using some of our original body-trigger designs, ${ }^{1418}$ we have been able to prepare AAs that generate PFBS, but, until now, we have never been able to prepare stable AAs that make acids any stronger than PFBS acid. Using the olefin $/ \alpha-\mathrm{CF}_{3}$ design, not only have we been able to prepare AAs that generate PFBS, but for the first time, we are able to prepare an AA that generates $\mathrm{TfOH}$

\subsubsection{Film Stability Studies}

One convenient method to assess the stability of a resist film is to measure its thickness as a function of temperature using temperature-programmed spectroscopic ellipsometry. ${ }^{20,21}$ We compared the thermal.

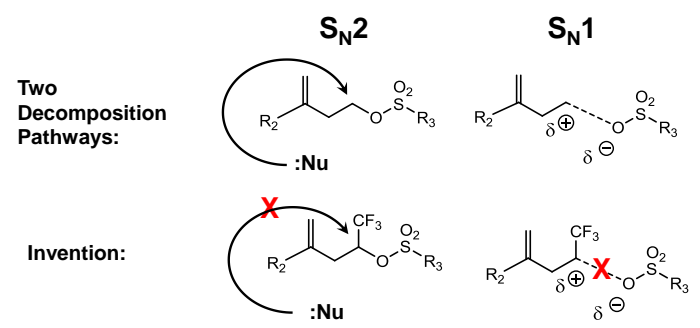

Figure 4. $\mathrm{CF}_{3}$ alpha to the sulfonic ester inhibits $\mathrm{S}_{\mathrm{N}} 2$ and $\mathrm{S}_{\mathrm{N}} 1$ reactions.
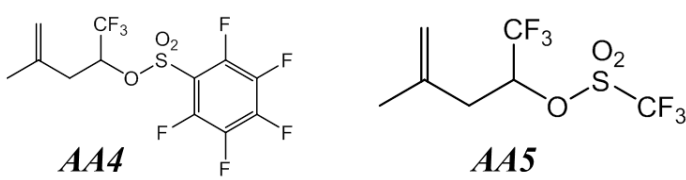

Figure 5. Chemical structures of fluorine stabilized AAs $\boldsymbol{A A 4}$ and $\boldsymbol{A A 5}$.

stability of a control resist, ${ }^{19} v s$. the analogous resists to

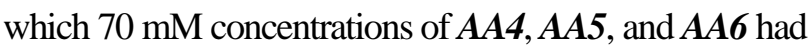
been added. The thickness curves (Figure 6) show that AA6 that produces $\mathrm{C}_{6} \mathrm{~F}_{5} \mathrm{SO}_{3} \mathrm{H}$ decomposes with peak decomposition rate of $125{ }^{\circ} \mathrm{C}$, whereas the resists prepared with $\boldsymbol{A A 4}$ and $\boldsymbol{A A 5}$ decompose at about the same temperature as the control resist $\left(195^{\circ} \mathrm{C}\right)$.

\subsection{2 ${ }^{19} \mathrm{~F}$ NMR Kinetics}

The rate of decomposition of $\boldsymbol{A A 4}$ and $\boldsymbol{A A 5}$ was determined using ${ }^{19} \mathrm{~F}$ NMR in the presence and absence of 1.2 eq. of base using previously described procedures (Figure 7). ${ }^{15} \quad$ These experiments determine the uncatalyzed and catalytic rate constants $\left(\mathrm{k}_{\mathrm{BASE}}\right.$ and $\mathrm{k}_{\mathrm{CAT}}$, respectively). These new AAs show dramatic stabilities at a temperature that is much higher than is typically used (145 vs. $100{ }^{\circ} \mathrm{C}$, respectively). For example, the AA that produces $\left(\mathrm{C}_{6} \mathrm{~F}_{5} \mathrm{SO}_{3} \mathrm{H}\right)$ only decomposes $10 \%$ after 29 days at $145{ }^{\circ} \mathrm{C}$. The kinetics conducted in the absence of base provide catalytic rate constants. ${ }^{22}$ We typically use the rate ratios of catalytic $v s$. noncatalytic acids as one criteria for judging the usefulness of an AA. This $\mathrm{k}_{\mathrm{CAT}} / \mathrm{k}_{\mathrm{BASE}}$ ratio should be as large as possible. The best rate ratio that we had observed previously for an $\mathrm{AA}$ that produced $\mathrm{C}_{6} \mathrm{~F}_{5} \mathrm{SO}_{3} \mathrm{H}$ was 300 , and the best ever observed was $1425 .{ }^{16}$ However, these new AAs based on olefin/ $\alpha$ $\mathrm{CF}_{3}$ design have rate ratios of $1,000,000$ and 28,000 for the AAs that produce $\mathrm{C}_{6} \mathrm{~F}_{5} \mathrm{SO}_{3} \mathrm{H}$ and $\mathrm{CF}_{3} \mathrm{SO}_{3} \mathrm{H}$, respectively.

2.2.3 Tuning the Reactivity of Stable Acid Amplifiers

After demonstrating the remarkable stabilizing effect of placing a $\mathrm{CF}_{3}$ group alpha to the sulfonic acid, we 


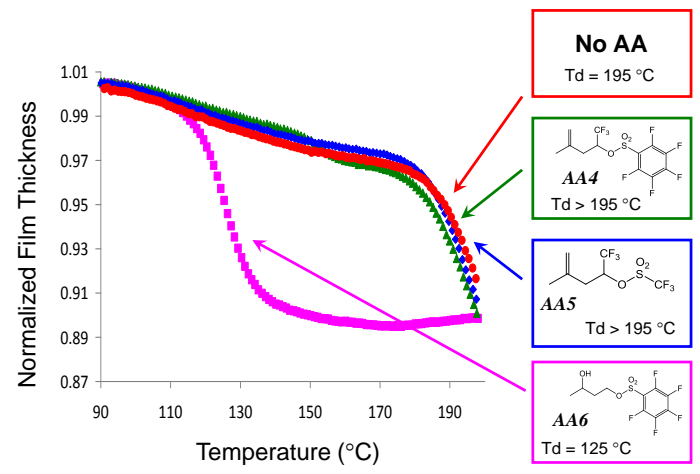

Figure 6. Thermally-programmed spectroscopic ellipsometry shows that AAs $\boldsymbol{A A 4}$ and $\boldsymbol{A A 5}$ are as thermally stable as the control resist without AA.
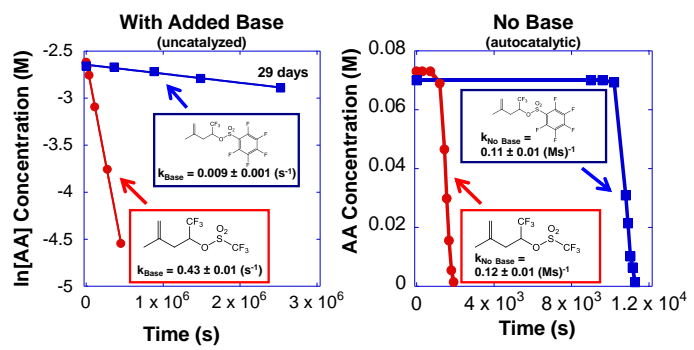

Figure 7. Thermal decomposition of $\boldsymbol{A A 4}$ and $\boldsymbol{A A 5}$ : A) With added base $B$ ) In the absence of base.

considered the possibility that the new body/trigger design might be too stable to be useful within the temperature range typically used during PEBs (90$\left.130{ }^{\circ} \mathrm{C}\right)$. We, therefore, produced new AAs that combined the alpha- $\mathrm{CF}_{3}$ body with the more reactive ketal triggers (Figure 8) and evaluated their effect of sensitivity (clearing dose, Eo) as a function of PEB bake $\left(100-130{ }^{\circ} \mathrm{C}\right)$. The new acid amplifiers provide 0-4X improvement in photosensitivity. Clearly, these new AAs are capable of participating in photoresist reactions within a useful range of PEB temperatures.

\subsubsection{Stability vs. pKa of Product Acid}

Figure 9 shows the first-order rate constants for 14 AAs arranged according to body/trigger type and the pKa calculated $^{26}$ for the sulfonic acid generated by the AA.

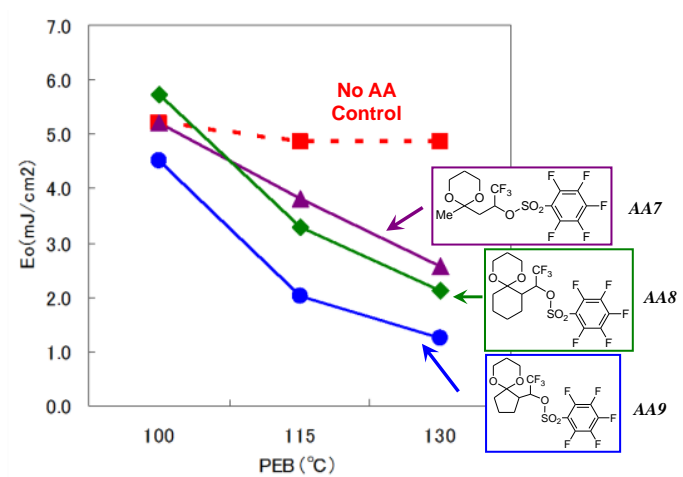

Figure 8. Clearing doses (Eo) of a control resist ${ }^{19}$ and resists

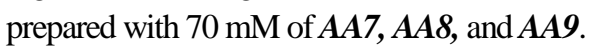

Interestingly, our new strategy for attaching AAs to polymers generate an acid with an amide linkage $\left(\mathrm{PhNHCOCF}_{2} \mathrm{SO}_{3} \mathrm{H}\right)$ which is predicted to be slightly stronger than triflic acid $\left(\mathrm{CF}_{3} \mathrm{SO}_{3} \mathrm{H}\right)$. Indeed, decomposition rate of an AA that generates our amidebased sulfonic acid is $3.5 \mathrm{x}$ faster than an AA that generates triflic acid. A plot of the log of the acid amplifier and first-order uncatalyzed rate constant $\left(\mathrm{k}_{\mathrm{BASE}}\right)$ is shown $v$ s. pKa (Figure 10). Clearly, the new olefin/ $\alpha$ $\mathrm{CF}_{3}$-type AAs demonstrate remarkable stability despite producing highly-fluorinated sulfonic acids. In fact, when comparing AAs that produce $\mathrm{C}_{6} \mathrm{~F}_{5} \mathrm{SO}_{3} \mathrm{H}$, the new design

\begin{tabular}{|c|c|c|c|c|c|c|}
\hline $\begin{array}{c}\text { Sulfonic } \\
\text { Acid } \\
\text { Predicted } \\
\text { pKa } \\
( \pm 0.5) \\
\end{array}$ & $\mathrm{OSO}_{2} \mathrm{P}$ & & & $\underbrace{\mathrm{O}^{\prime}}_{\mathrm{OSO}_{2} \mathrm{R}}$ & OSO & $Y_{\mathrm{OSO}_{2} \mathrm{R}}^{\mathrm{CF}_{3}}$ \\
\hline (1.1 & 16 & 3.6 & 1.2 & & & $\begin{array}{c}\text { Most } \\
\text { Stable }\end{array}$ \\
\hline $\begin{array}{l}\mathrm{SO}_{3} \mathrm{H} \\
-1.2\end{array}$ & 21 & 5.1 & 1.7 & & & \\
\hline$N^{F}$ & 240 & 73 & & & & $0.009^{\star}$ \\
\hline $\begin{array}{r}\mathrm{CF}_{3}-\mathrm{SO}_{3} \mathrm{H} \\
-3.9\end{array}$ & & & & & & $0.43^{*}$ \\
\hline 1) $y^{\mathrm{N}}{ }^{\mathrm{F}} \mathrm{K}^{\mathrm{F}}{ }^{\mathrm{SO}_{3} \mathrm{H}}$ & $\begin{array}{l}\text { Least } \\
\text { Stable }\end{array}$ & & & $\begin{array}{c}0.82 \\
54^{*}\end{array}$ & $\begin{array}{c}0.036 \\
3.8^{\star}\end{array}$ & $\begin{array}{c}0.028 \\
1.5^{\star}\end{array}$ \\
\hline
\end{tabular}

Figure 9. First-order rate constants $\left(\times 10^{-5} \mathrm{~s}^{-1}\right)$ vs. calculated pKas of product acids at $100^{\circ} \mathrm{C}$ or if marked with, *, at $145^{\circ} \mathrm{C}$. 


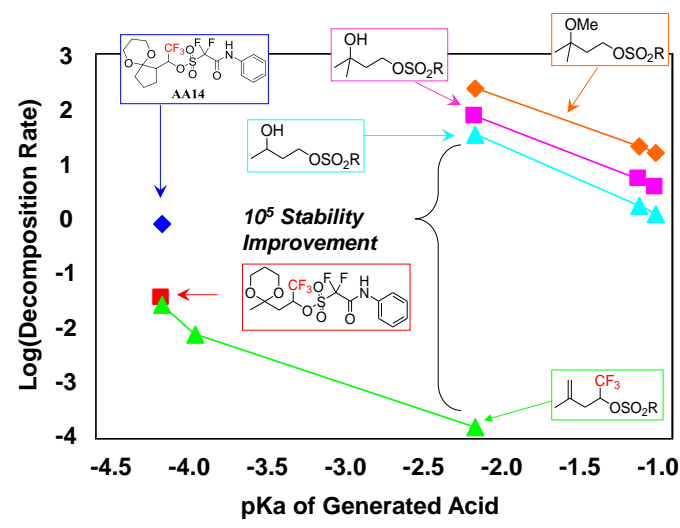

Figure 10. $\log ($ decomposition rate) in the presence of excess base $v s$. calculated $\mathrm{pKa}$ of acids produced by AAs.

provides a $100,000 \mathrm{X}$ improvement in stability over the most stable AAs previously evaluated. Interestingly, AA14 may have the right balance between stability and reactivity, by combining the strongly acidic amide acid precursors with the spiro-ketal trigger design.

2.3 Synthesis and Preliminary Lithographic Performance of Fluorine-Stabilized Polymers

We prepared three monomers based on the alpha- $\mathrm{CF}_{3}$ stabilization and ketal triggers that have a para-amidestyrene functionality capable of participating in polymerization reactions as described elsewhere ${ }^{24}$ and shown in Figure 11.

Preliminary lithographic performance of resists prepared with blend and polymer-bound fluorinestabilized AA against AA-free controls were evaluated at the Paul Sherrer Institut (PSI) using EUV interference lithograpy. ${ }^{25}$ Resists were prepared with $10 \%$ DTBPI-Nf PAG and either 1 or $2 \%$ base (Figure 12 and 13, respectively) and were used to print 50-nm dense lines.

The control resist prepared with $1 \%$ base produced an LER of $5.6 \pm 0.4 \mathrm{~nm}$ (Figure 12). Blending $70 \mathrm{mM}$ of $\boldsymbol{A A 1 0}$ provided an improvement in LER to $3.1 \pm 0.1 \mathrm{~nm}$. The polymer bound AA (PBAA11) also showed an improvement in LER to $3.8 \pm 0.4 \mathrm{~nm}$.

The control resist prepared with $2 \%$ base produced an LER of $4.6 \pm 0.5 \mathrm{~nm}$ (Figure 13). Blending $70 \mathrm{mM}$ of
$\boldsymbol{A A 1 2}$ showed no significant improvement in LER, yet blends of $\boldsymbol{A A 1 0}$ produced an LER of $2.1 \pm 0.2 \mathrm{~nm}$. The polymer-bound AA, $\boldsymbol{P B A A 1 3}$, provided a modest improvement in LER of $3.8 \pm 0.1 \mathrm{~nm}$.

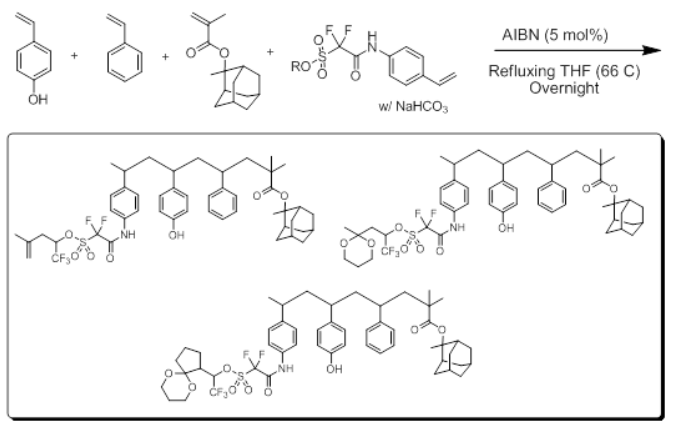

Figure 11. Synthesis of polymers starting with a monomer that generated a polymer-bound AA.

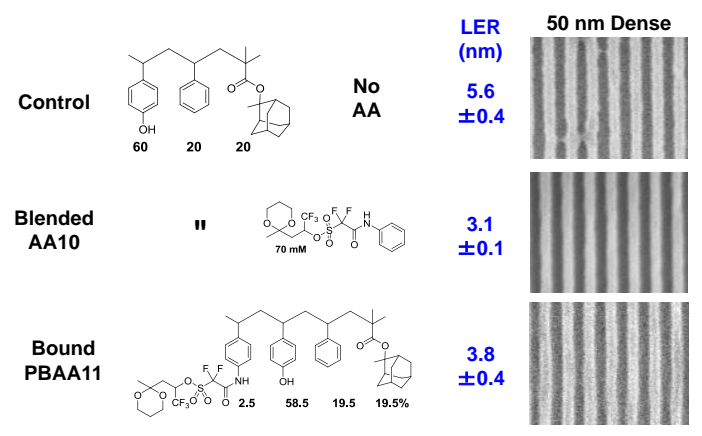

Figure 12. Lithographic properties of new acid amplifiers. Base loading $=1.0 \%$

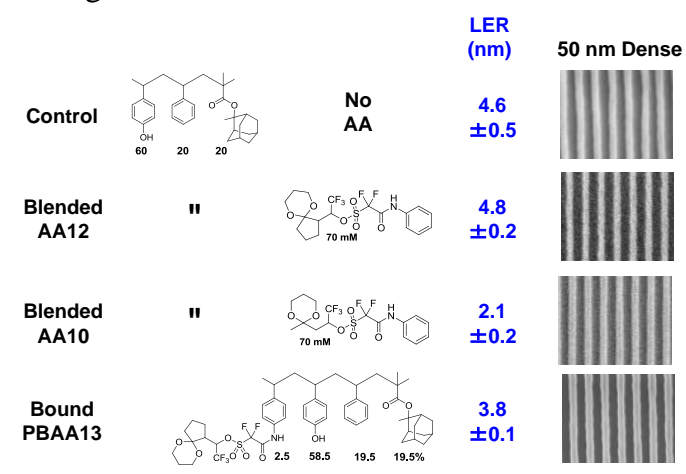

Figure 13. Lithographic properties of new acid amplifiers. Base loading $=2.0 \%$

\section{Conclusions}

Two new AA design strategies have been presented based on olefin triggers and trifluoromethyl groups 
positioned alpha to sulfonic ester groups. Comparison between previous body-trigger design strategies show:

- A 100,000X improvement in thermal decomposition stability for AAs that produce $\mathrm{C}_{6} \mathrm{~F}_{5} \mathrm{SO}_{3} \mathrm{H}$.

- The first stable AA capable of producing the very strong triflic acid $\left(\mathrm{CF}_{3} \mathrm{SO}_{3} \mathrm{H}\right)$.

- Dramatic improvement in the $\mathrm{k}_{\mathrm{CAT}} / \mathrm{k}_{\mathrm{BASE}}$ reactivity ratio from the previous high of 1425 to 38,000 and $1,000,000$ for $\boldsymbol{A A 5}$ and $\boldsymbol{A} \boldsymbol{A} 4$, respectively.

New ketal-triggered AAs were presented that provide good sensitivity enhancement of the fluorine-stabilized AAs within useful PEB temperature range. Additionally, these new AAs are sufficiently stable enabling them to be converted to styrene-based monomers capable of being incorporated into polymers via overnight free radical polymerization reactions.

Although the lithographic results are very preliminary, and lack information about sensitivity, ${ }^{25}$ the significant improvements in LER provide strong evidence that fluorine-stabilized acid amplifiers have a promising future for use in chemically amplified resists.

\section{Acknowledgements}

The authors of this paper would like to thank Central Glass, Co. Ltd. for financial support of this research and would like to thank Intel Corporation for the original funding. We thank Dow Electronic Materials for supplying us with monomers. We also thank the staff at PSI (Yasin Ekinci, Michaela Vockenhuber) for assistance in conducting lithographic evaluations, and thank Alain Diebold for help with Ellipsometry. Lastly, we thank Patrick Naulleau and Summit Corporation for providing an academic license to Summit

\section{References}

[1] M. D. Shumway, P. Naulleau, K. A. Goldberg, and J. Bokor, J. Vac. Sci. Tech., B, 23 (6) (2005),. 28442847.

[2] G. Gallatin, M. Gregg P. Naulleau, D. Niakoula, R. L. Brainard, E. Hassanein, R. Matyi, J. Thackeray, K. Spear, and K. Dean, Proceed. SPIE, 6921 (2008), . 69211E/1-69211E/11.
[3] R. L. Brainard, P. Trefonas, J. H. Lammers, C. A. Cutler, J. F. Mackevich, A. Trefonas, and S. A. Robertson, Proceed. SPIE, 5374 (2004),. 74-85.

[4] K. Ichimura, Chem. Rec., 2(1) (2002),. 46-55.

[5] C. J. Gerdts, D. E. Sharoyan, and R. F. Ismagilov, J. Am. Chem. Soc., 126(20) (2004), 6327-6331.

[6] S-W. Park, K. Arimitsu, and K. Ichimura, Macromol. Rap. Com., 21 (2000), 1050.

[7] S. Noguchi, K. Arimitsu, K. Ichimura, K. Kudo, T. Ohfuji, and M. Sasago, J. Photopoly. Sci. Tech., 1997, 10, p. 315.

[8] O. T. Naito, M. Endo, H. Morimoto, K. Arimitsu, and K. Ichimura, J. Photopoly. Sci. Tech., 12 (1999), 509.

[9] S-W. Park, K. Arimitsu, K. Ichimura, and T. Ohfuji, J. Photopoly. Sci. Tech., 12 (1999), 293.

[10] K. Kudo, K. Arimitsu, H. Ohmori, H. Ito, and K. Ichimura, Chem. Mat., 11 (1999) 2119.

[11] H. Ito, and K. Ichimura, Macromol. Chem. Phys., 201 (2000), 132.

[12] K. Arimitsu, K. Kudo, and K. Ichimura, J. Am. Chem. Soc., 120 (1998), 37.

[13] S. Lee, K. Arimitsu, S-W. Park, and K. Ichimura, J. Photopoly. Sci. Tech., 13 (2000), 215.

[14] S. A. Kruger, "Fluorinated acid amplifiers for extreme ultraviolet lithography", Ph.D. Thesis, University at Albany, Albany, MY, 2011.

[15] S. A. Kruger, C. Higgins, B. Cardineau, T. R. Younkin, and R. L. Brainard, "Catalytic and Autocatalytic Mechanisms of Acid Amplifiers for Use in EUV Photoresists," Chem. Mat., 22 (19) (2010), 5609-5616.

[16] S. A. Kruger, S. Revuru, C. Higgins, S. Gibbons, D. A. Freedman, W. Yueh T. Younkin, and R. L. Brainard, "Fluorinated Acid Amplifiers for EUV Lithography," J. Am. Chem. Soc., 131(29) (2009), 9862-9863.

[17] S. A. Kruger, C. Higgins, S. Revuru, S. Gibbons, D. Freedman, and R. L. Brainard, "Can acid amplifiers help beat the resolution, line edge roughness and sensitivity trade-off?" Jap. J. App. Phys., 49(4) (2010), 041602/1-041602/5. 
[18] R. L. Brainard, S. Kruger, C. Higgins, S. Revuru, S. Gibbons, D. Freedman, Y. Wang, T. Younkin, $J$. Photopoly. Sci. Tech., 22 (2009), 43-50.

[19] The control resist for these experiments was OS3 which is composed of, a mass fraction of $7.5 \%$ of the photoacid generator bis(4-tert-butylphenyl)iodonium nonaflate the phenolic terpolymer [poly(hydroxystyrene)-(styrene)-(t-buylacrylate) $650 / 200 / 150 \mathrm{mmol} / \mathrm{mol}$ ] and a mass fraction of $1.0 \%$ of tetrabutyl ammonium hydroxide.

[20] Thermally-programmed spectroscopic ellipsometry was used to measure the film thickness as a function of temperature. When AAs thermal decomposed they released acid which deprotected the polymer causing isobutene to outgas. The outgassing resulted in a sudden decrease in film thickness which was measured by the ellipsometer.

[21] H. G. Tompkins, "A user's guide to ellipsometry," Academic Press, 1993, San Diego, CA.

[22] The thermal decomposition kinetics of the AAs in solution (in sealed NMR tubes) were measured using ${ }^{19} \mathrm{~F}$ NMR. Solutions of AAs $(70 \mathrm{mM})$ in $50 / 50$ wt\% $\quad \mathrm{C}_{6} \mathrm{D}_{6} /$ m-ethylphenol (to simulate the environment of a phenolic polymer matrix) in the presence and absence of 1.2 eq. of added 2,4,6-tri-tbutylpyridine were monitored. The stericallyhindered base was added to consume acid as it formed, so that the uncatalyzed reactions could be studied independently. We chose to compare rate constants at $100{ }^{\circ} \mathrm{C}$ because they can be measured accurately at this temperature for all AA that were investigated in the presence and absence of added base. For extremely stable AAs, we studied decomposition rate at $145{ }^{\circ} \mathrm{C}$. The decomposition rate of one AA was evaluated at both 100 and $145^{\circ} \mathrm{C}$. Its decomposition rate was 26 times higher at 145 than at $100{ }^{\circ} \mathrm{C}$. We used this rate ratio to compare the relative rates of compounds studied at different temperatures.

[23] Second-order catalyzed reaction kinetics were evaluated by fitting data to the autocatalytic rate equation. Capellos, Christos, and B. Bielski, "Kinetics Systems, Mathematical Description of Chemical Kinetics in Solution", Wiley-Interscience, New York (1972).

[24] K. Hosoi, B. Cardineau, W. Earley, S. Kruger, K. Miyauchi, R. Brainard; "Synthesis of Stable Acid Amplifiers that Produce Strong, Highly Fluorinated Polymer Bound Acid" 2012 SPIE proceedings.

[25] Typically, the synchrotron at PSI is extremely stable. Unfortunately, during the week of these experiments, the intensity of the EUV source was variable, so we were unable to provide the doses of these preliminary experiments.

[26] $\mathrm{pKa}$ values were calculated using Advanced Chemistry Development software V11.02. 